\title{
RESEARCH
}

Open Access

\section{Disparities in cervical screening participation: a comparison of Russian, Somali and Kurdish immigrants with the general Finnish population}

Esther E. Idehen ${ }^{1 *}$, Päivikki Koponen ${ }^{2}$, Tommi Härkänen², Mari Kangasniemi ${ }^{3}$, Anna-Maija Pietilä3 and Tellervo Korhonen ${ }^{1,4}$

\begin{abstract}
Background: Cervical cancer is currently ranked as the fourth commonly diagnosed cancer in women globally. A higher incidence has been reported in low- and-middle-income countries, and the disease poses significant public health challenges. Evidence suggests that this disease is preventable by means of regular screening using the Papanicolaou (Pap) test. However, limited knowledge exists about disparities in cervical screening participation among immigrants compared with non-immigrants, in countries with universal cervical screening programmes. We aimed to examine disparities in cervical screening participation among women of Russian, Somali, and Kurdish, origin in Finland, comparing them with the general Finnish population (Finns). We controlled for differences in several socio-demographic and health-related variables as potential confounders.

Methods: We employed data from the Finnish Migrant Health and Well-being Study 2010-2012 and the National Health 2011 Survey. Data collection involved face-to-face interviews. Data on screening participation in the previous five years from women aged 29-60 were available from 537 immigrants (257 Russians, 113 Somalis, 167 Kurds) and from 436 Finns. For statistical analyses, we used multiple logistic regression.

Results: Age-adjusted screening participation rates were as follows: Russians 79\% (95\% Cl 72.9-84.4), Somalis 41\% (95\% Cl 31.4-50.1), and Kurds 64\% (95\% Cl 57.2-70.8), compared with 94\% (95\% Cl 91.4-95.9) among Finns. After additionally adjusting for socio-demographic and health-related confounders, all the immigrant groups showed a significantly lower likelihood of screening participation when compared with Finns. The Odds Ratios were as follows: Russians 0.32 (95\% Cl 0.18-0.58), Somalis 0.10 (95\% Cl 0.04-0.23), and Kurds 0.17 (95\% Cl 0.09-0.35). However, when additionally accounting for country of origin-confounder interactions, such differences were attenuated.

Conclusions: Our results indicate disparities in screening participation among these immigrants and a lower likelihood of screening participation compared with the general Finnish population. To improve equity in cervical cancer screening participation, appropriate culturally tailored intervention programmes for each immigrant group might be beneficial.
\end{abstract}

Keywords: Cervical cancer, Cervical screening, Equity, Disparities, Healthcare service, Health inequities, Immigrants, Pap test

\footnotetext{
* Correspondence: estheri@uef.fi; estheri@hotmail.com

${ }^{1}$ Institute of Public Health and Clinical Nutrition, Faculty of Health Sciences,

University of Eastern Finland, Yliopistoranta 1, P. O. Box 1627, 70211 Kuopio,

Finland

Full list of author information is available at the end of the article
}

(c) The Author(s). 2018 Open Access This article is distributed under the terms of the Creative Commons Attribution 4.0 International License (http://creativecommons.org/licenses/by/4.0/), which permits unrestricted use, distribution, and reproduction in any medium, provided you give appropriate credit to the original author(s) and the source, provide a link to the Creative Commons license, and indicate if changes were made. The Creative Commons Public Domain Dedication waiver (http://creativecommons.org/publicdomain/zero/1.0/) applies to the data made available in this article, unless otherwise stated. 


\section{Background}

Cervical cancer is currently ranked as the fourth commonly diagnosed cancer in women globally [1, 2]. A higher incidence of the disease has been reported in low- and-middle-income countries (LMICs) [1]. Worldwide, approximately 528,000 new cases of cervical cancer and 266,000 deaths resulting from the disease were reported in 2012. Nearly $90 \%$ of that mortality was in LMICs [1, 3]. Considerable evidence proves that the Papanicolaou (Pap) test is an effective screening tool for early detection of "pre-cancerous lesions," with a followup procedure and a better prognosis [3-5]. Therefore, cervical screening and follow-up are recommended for all asymptomatic women $[5,6]$, irrespective of cultural background. The incidence of, and mortality resulting from cervical cancer have substantially declined in most developed countries $[3-5,7,8]$. However, the use of this healthcare service in some countries offering universal cervical screening involves significant racial or ethnic disparities [9-19]. This reflects that having the right, or equal access, to healthcare services, such as cervical screening, does not guarantee equal utilisation of the service $[12,20]$.

It is essential to explore disparities in cervical screening participation among various immigrant groups and non-immigrants, even when universal screening exits. Previous studies have revealed a higher risk of cervical cancer among women who seldom participate in screening or those not screened, compared with regularly screened women [21, 22]. Notably, studies have reported a higher risk of the disease among some immigrant groups compared with non-immigrants in several countries offering a universal screening programme $[4,11,12,16,23]$.

Previous international studies have indicated that some socio-economic and health-related determinants are associated with non-adherence to screening recommendations. Thus, differences in these determinants would indicate additional potential disparities, which may confound disparities observed in cervical screening. Such determinants include a low educational level, unemployment, being unmarried, limited language proficiency, lack of knowledge of screening, and previous unpleasant screening experiences [9, 13, 17, 18, 23-26]. Other determinants are related to cultural beliefs and health-seeking behaviour found among some ethnic groups [14, 19, 27-29]. Additionally, migration-related issues have been highlighted as significant predictors associated with disparities in the screening participation. For example, younger age at migration, longer length of stay in the host country, and a higher level of acculturation, are determinants for a higher likelihood of screening participation among some immigrant groups $[10,26,30-33]$. Barriers to screening participation include limited understanding of screening and low level of education in the country of origin before migrating to the host country. Inability to navigate within the healthcare system and difficulties in obtaining health information are also barriers [24, 31, 33, 34].

Global mobility as a result of various factors, such as employment, war crises, education, and family reunion, raised international migrant numbers to 244 million in 2015. Approximately half $(52.4 \%)$ of these migrants are women; [35] the migrant European population has also grown, with about 76 million migrants [36]. People from different cultures might have different expectations based on their health values and beliefs dependent on cultural norms [37]. These might influence their use of healthcare services, such as cervical screening participation. More recently, the health status of some immigrant groups referred to as "vulnerable populations" as compared with that of non-immigrants has drawn attention in the European public health sector [20,38]. As such, great concern exists that immigrants referred to as "hard to reach" might lack access to healthcare services, such as screening, compared with the native population [26, 33]. Hence, the World Health Organisation and the European Commission have set equity in healthcare as a top priority goal in its member states, to address inequity in healthcare and to improve healthcare service practices and delivery [20, 38-40].

Finland has witnessed a substantial growth in its immigrant population, including women, in recent years. According to Statistics Finland, the immigrant population increased by $21 \%$ in 2016 , compared to a year earlier [41]. Finland has offered organised mass cervical screening programme since the 1960 s, using a five-year interval among women aged 25-65 [42, 43]. Personal screening invitation letters are sent to all eligible women, including immigrants, identified from the Finnish national population register [43]. In addition, women in this age group can participate in other (opportunistic) screening tests offered, or referred to, by their physicians or other healthcare providers [44]. Hence, in Finland, the effectiveness of cervical screening is well established $[3,7,8,45]$. For instance, cervical screening coverage among those invited to mass screening is approximately $70 \%$ [43], and screening coverage among the general Finnish population is nearly 90\% [44]. The incidence of cervical cancer is about $4 / 100,000$, and mortality resulting from cervical cancer is around $1 / 100,000$ women [43].

A previous study in Finland revealed relatively low screening participation rates as well as differences in, and significant barriers to cervical screening among some immigrant groups [9]. However, knowledge is limited about potential disparities in the screening participation among different population groups compared with the general Finnish population. 
In this study, we aimed to examine disparities in selfreported cervical screening (Pap test) participation among women of Russian, Somali, and Kurdish, origin in Finland, compared with the general Finnish population (hereafter, Finns). We controlled for differences in several socio-demographic and health-related variables as potential confounders. With the increasing population of various immigrant groups, it is essential to explore disparities in cervical screening participation and identifying groups at risk of the disease. This study will potentially contribute to the existing knowledge of cervical screening participation among various immigrant groups. Additionally, we hope to aid policy making and to develop effective screening programmes tailored to immigrants and appropriate healthcare resource allocation, both at national and international levels.

\section{Methods}

\section{Study population}

We employed data from the Finnish population-based Migrant Health and Well-being Study (Maamu) 2010-2012 [46] and the National Health 2011 Survey [47] conducted by the Finnish National Institute for Health and Welfare (THL). The Maamu study sample consists of 3000 immigrants: 1000 from Russia or the former Soviet Union, 1000 from Somalia, and 1000 from Iraq or Iran (Kurdish background) [46]. These immigrant groups represent various geographical regions and reasons for migration. Among foreign language speakers in Finland, Russians are the largest group and Somalis the fourth largest; Kurdish Sorani speakers comprise the sixth largest group. Recently, Kurds from Iraq and Iran have been among the major groups in the quota of refugees accepted into Finland [48]. Our Somali group comprises mainly refugees and those women who came to Finland for reuniting with their families.

A random sample was drawn from the Finnish National Population Registry and stratified by municipality and participants' country of origin [46]. The inclusion criteria were as follows: country of birth (Russia/Soviet Union, Somalia, Iraq or Iran) and mother tongue, as recorded in the population register. We included Russians (speaking Russian or Finnish) and Kurds (speaking Kurdish Sorani), the latter born in Iraq or Iran. Other inclusion criteria were age 18-64, living in one of the six Finnish cities with high proportions of immigrants (Helsinki, Espoo, Vantaa, Tampere, Turku, and Vaasa), and at least one year of stay in Finland.

Among the 3000 persons (1000 from each immigrant group) invited to the survey, the minimum participation rates for any one part of the study protocol were as follows: Russians 70\% $(n=702)$, Somalis 51\% $(n=512)$, and Kurds, 63\% $(n=632)$. The study protocol included a face-to-face interview as well as a health examination and a health interview, with an option for a short interview for those unable or unwilling to participate in the longer health examination or interview. We analysed 537 responses on self-reported cervical screening participation in the previous five years; we obtained these from immigrants (257 Russians, 113 Somalis, 167 Kurds) aged 29-60, the recommended age range for the Finnish mass screening programme [43]. The Finnish reference group comprised participants from the National Populationbased Health 2011 Survey, who lived in the same six cities as the participants in the Maamu survey. Approximately, $71 \%$ of them participated in at least one part of the study $(n=1582)$ [47]; from this reference group, we had 436 respondents.

\section{Data collection methods}

The Maamu study comprises data from structured face-to-face interviews conducted by trained bilingual interviewers who used the native languages of the participants. The interviews consisted of questions on socio-economic- and health-related issues, including cervical screening participation. The Health 2011 survey data were collected using face-to-face interviews and self-administered questionnaires.

\section{Measures and variables}

Based on the Finnish recommendation for the organised screening programme, the dependent variable in the study was self-reported cervical screening (Pap test) participation in the previous five years. As part of the health interview, participants were asked about any Pap test taken, including tests in the organised screening programme and in non-organised settings, such as private clinics (opportunistic tests); the answers were recorded as 'yes' or 'no.'

Based on earlier studies indicating determinants associated with screening participation [10, 13, 14, 18, 23, 26, 29], our analyses considered differences in several potential confounders. We selected several potential confounders in the socio-demographic category: age, level of education, marital status, number of household members, employment status, residential area, and income sufficiency. Health-related confounders included self-perceived health status and leisuretime physical exercise; we asked them whether they had had a chronic illness, abortion, or miscarriage; participants also responded to whether they were obese $(\mathrm{BMI}>30)$ and to whether they had ever smoked or given birth.

\section{Statistical analyses}

For statistical analyses, we used the StataSE/13 software package. All analyses used finite population correction (FPC), with the effects of non-response corrected with Inverse Probability Weighting (IPW) [49]. The logistic regression model used for IPW was based on register 
information on the immigrant groups, age group, gender, city, and marital status. The weights were calibrated using the population size of each stratum. Using predictive margins, we calculated the adjusted prevalence estimates [50]. First, we analysed the main descriptive characteristics of the study population, i.e., weighted and age-adjusted prevalence (\%) estimates for categorical variables and mean, plus standard error (SE) for the continuous variable (age). Further, we applied multiple logistic regression models to explore the statistical significance of the disparities in screening participation among these immigrant groups compared with Finns, the reference group $(\mathrm{OR}=1.00)$. Model 1 was adjusted for only age while model 2 was additionally adjusted for the main effects of selected socio-demographic and health-related confounders. Then we tested country of origin-confounder interactions on screening participation, with $p<0.15$ as a threshold. We included those country of originconfounder interactions in Model 3, which was the final model based on the analyses.

\section{Results}

Descriptive results

Age-adjusted screening participation rates were as follows: Russians 79\% (95\% CI 72.9-84.4), Somalis 41\% (95\% CI 31.4-50.1), and Kurds 64\% (95\% CI 57.2-70.8), compared with 94\% (95\% CI 91.4-95.9) among Finns. Table 1 displays the descriptive characteristics of the study participants.

\section{Screening participation dependent on country of origin-confounding variable interactions}

Table 2 shows age-adjusted prevalence estimates of the screening participation based on the most essential confounding variables, which had significant interactions with the country of origin of these immigrant groups. Married Finns and Somalis participated in screening more often while Russians and Kurds tended to be the opposite. Employed Russians and Kurds participated more actively; employed Finns and Somalis, however, tended to participate less actively. Russians and Somalis having one to three household members participated more, but the opposite was true for Kurds and Finns. Those living outside of the metropolitan areas of Finland had higher screening participation among all the groups, except for the Somalis (Table 2).

Table 3 displays the Odd Ratios [ORs] and 95\% Confidence Intervals [CIs] of three logistic regression models for screening participation among the immigrant groups compared with the reference group (Finns' OR $=1.00$ ). When adjusted for only age, the likelihood of screening participation among all the immigrant groups was

Table 1 Characteristics of participants by country of origin: weighted and age-adjusted proportions (\%)

\begin{tabular}{|c|c|c|c|c|c|c|c|c|c|c|}
\hline \multirow{2}{*}{\multicolumn{3}{|c|}{$\begin{array}{l}\text { Characteristics } \\
\text { Age: Years Mean (SE) }\end{array}$}} & \multirow{2}{*}{\multicolumn{2}{|c|}{$\frac{\text { Finnish }(n=436)}{44.9(0.46)}$}} & \multirow{2}{*}{\multicolumn{2}{|c|}{$\frac{\text { Russian }(n=257)}{44.8(0.61)}$}} & \multirow{2}{*}{\multicolumn{2}{|c|}{$\frac{\text { Somali }(n=113)}{40.8(0.81)}$}} & \multirow{2}{*}{\multicolumn{2}{|c|}{$\frac{\text { Kurdish }(n=167)}{40.3(0.56)}$}} \\
\hline & & & & & & & & & & \\
\hline Variable & Description & $\begin{array}{l}\text { Total } n \text { of } \\
\text { respondents }\end{array}$ & $n$ & $\%$ & $n$ & $\%$ & $n$ & $\%$ & $n$ & $\%$ \\
\hline $\begin{array}{l}\text { Pap test taken in the past } \\
\text { five years }\end{array}$ & Yes & 973 & 405 & 93.6 & 198 & 78.6 & 39 & 40.8 & 106 & 64.0 \\
\hline Education & High school in any country & 971 & 313 & 74.8 & 218 & 87.6 & 14 & 15.6 & 68 & 43.9 \\
\hline Marital status & Married or cohabiting & 970 & 305 & 73.9 & 170 & 67.0 & 84 & 78.8 & 129 & 75.4 \\
\hline Household members & Above three members & 973 & 117 & 36.0 & 55 & 26.6 & 83 & 77.0 & 92 & 55.4 \\
\hline Employment status & Employed & 970 & 359 & 79.8 & 143 & 51.7 & 16 & 15.1 & 55 & 32.9 \\
\hline Residential area & $\begin{array}{l}\text { Outside metropolitan } \\
\text { areas }\end{array}$ & 973 & 118 & 24.9 & 89 & 16.4 & 31 & 9.4 & 67 & 43.2 \\
\hline Sufficient income & Yes & 959 & 288 & 69.8 & 121 & 48.0 & 54 & 42.1 & 55 & 34.1 \\
\hline Self-perceived health status & Good & 973 & 357 & 86.1 & 137 & 61.9 & 85 & 74.1 & 87 & 56.2 \\
\hline Ever given birth & Yes & 928 & 293 & 60.9 & 223 & 79.9 & 99 & 92.8 & 157 & 92.4 \\
\hline Ever smoked & Yes & 972 & 330 & 78.6 & 146 & 59.7 & 3 & 4.0 & 17 & 10.1 \\
\hline Obese & $\begin{array}{l}\text { Body Mass Index (BMI) } \\
\geq 30 \mathrm{~kg} / \mathrm{m} 2\end{array}$ & 962 & 91 & 16.6 & 54 & 17.5 & 49 & 42.2 & 47 & 27.6 \\
\hline Leisure-time physical exercise & Active & 938 & 103 & 28.9 & 61 & 28.7 & 15 & 19.5 & 29 & 19.6 \\
\hline Any chronic illness & Yes & 972 & 137 & 25.1 & 110 & 39.0 & 28 & 26.9 & 69 & 39.8 \\
\hline Any abortion & Yes & 920 & 74 & 15.1 & 157 & 58.9 & 3 & 1.0 & 45 & 26.9 \\
\hline Any miscarriage & Yes & 924 & 78 & 18.2 & 59 & 19.8 & 43 & 38.8 & 55 & 31.6 \\
\hline
\end{tabular}

${ }^{\mathrm{a}}$ For age, mean and Standard Error (SE)

${ }^{\mathrm{b}}$ Among women who responded to the question of Pap test participation $(n=973)$ 
Table 2 Age adjusted prevalence of Pap test participation by confounding variables with country of origin interactions

\begin{tabular}{|c|c|c|c|c|}
\hline \multirow[t]{2}{*}{ Variables } & Finnish & Russian & Somali & Kurdish \\
\hline & $\%$ & $\%$ & $\%$ & $\%$ \\
\hline \multicolumn{5}{|l|}{ Marital status } \\
\hline Married or cohabiting & 96.5 & 73.7 & 46.4 & 63.7 \\
\hline Others $^{a}$ & 87.5 & 78.8 & 38.8 & 66.5 \\
\hline \multicolumn{5}{|l|}{ Employment status } \\
\hline Employed & 91.2 & 82.5 & 38.7 & 73.8 \\
\hline Not employed & 94.7 & 68.9 & 49.2 & 55.2 \\
\hline \multicolumn{5}{|l|}{ Household members } \\
\hline One-three members & 92.5 & 76.7 & 46.6 & 58.8 \\
\hline Above three members & 94.9 & 73.4 & 38.0 & 76.3 \\
\hline \multicolumn{5}{|l|}{ Residential areas } \\
\hline Metropolitan areas ${ }^{b}$ & 92.4 & 73.5 & 53.9 & 59.9 \\
\hline Other cities/outside of metropolitan areas ${ }^{c}$ & 95.1 & 81.3 & 14.5 & 78.5 \\
\hline
\end{tabular}

ancluding the singles, separated or divorced, and widow

${ }^{b}$ Metropolitan areas (Helsinki, Espoo, and Vantaa)

'Other cities (Tampere, Turku and Vaasa)

significantly lower. Compared with the reference group, Somalis had the lowest odds (Model 1). After adjusting for age and socio-demographic and health-related confounders, these disparities remained significant compared with the reference group; all our immigrant groups demonstrated a significantly lower likelihood of screening participation (Model 2).

Model 3 provided the results adjusted for the direct effects of multiple confounders and included countryconfounder interactions. Those confounders which had major effects were age, socio-demographic (education and income) and health-related variables. Health-related confounders included self-perceived health status and leisure-time physical exercise; we asked them whether they had had a chronic illness, abortion, or miscarriage; participants also responded to whether they were obese $(\mathrm{BMI}>30)$ and to whether they had ever smoked or given birth. Country of origin and the following confounding variables exhibited significant interaction: marital status, employment status, number of household members, residential area, and whether they had ever smoked.

When we adjusted the final model simultaneously for these confounders and interactions, compared with the reference group, we still detected lower OR point estimates of screening participation among all these immigrant groups. However, none of the ORs remained statistically significant, as indicated by the $95 \%$ CIs which include 1 (Table 3 ).

\section{Discussion}

The rationale behind cervical screening using the Papanicolaou (Pap) test is early detection of "pre-cancerous lesions" and effective treatment of abnormalities [3-5].
However, full compliance with screening recommendations is essential to achieve this goal. This populationbased study examined disparities in cervical screening (Pap test) participation among women of Russian, Somali, and Kurdish, origin residing in Finland and compared it with the general Finnish population (Finns), our reference group. In our analyses, we accounted for country of origin differences in multiple determinants of cervical screening were considered as potential confounders. We also accounted for multiple country of originconfounder interactions. The lower odds for screening participation compared with the Finns indicated significant disparities among the immigrant groups studied. However, such disparities were attenuated when accounting for socio-demographic and health-related confounders specific to each immigrant group. Thus, we demonstrated that multiple screening determinants specific to each country of origin might underlie the disparities initially observed.

Although Finland offers universal cost-free cervical screening to all eligible women, including legal immigrants, our findings demonstrate disparities among these immigrants and lower screening participation in comparison with the Finns. Our results are consistent with previous international studies showing disparities in screening participation among various immigrant groups in countries offering universal screening programmes [10-13, 16-18, 23]. Although such disparities have been widely reported world-wide, to the best of our knowledge, similar disparities in Finland have not been published earlier.

The main goal of universal healthcare is that "all people can obtain the health services they need without suffering 
Table 3 Logistic regression models for Pap test participation: Odds Ratios (OR) and 95\% Confidence Intervals (Cl)

\begin{tabular}{|c|c|c|c|c|c|c|c|}
\hline \multirow[t]{2}{*}{ Variables } & & \multirow[t]{2}{*}{ Main effects } & \multirow{2}{*}{$\begin{array}{l}\text { Finnish } \\
\text { OR }\end{array}$} & \multirow{2}{*}{$\begin{array}{l}\text { Russian } \\
\text { OR (95\% Cl) }\end{array}$} & \multirow{2}{*}{$\begin{array}{l}\text { Somali } \\
\text { OR (95\% Cl) }\end{array}$} & \multirow{2}{*}{$\begin{array}{l}\text { Kurdish } \\
\text { OR (95\% Cl) }\end{array}$} & \multirow[t]{2}{*}{$P$} \\
\hline & & & & & & & \\
\hline Model $^{1}$ & & OR $(95 \% \mathrm{Cl})$ & 1.00 & $0.25(0.15-0.40)$ & $0.05(0.03-0.08)$ & $0.12(0.07-0.19)$ & \\
\hline Model $^{2}$ & Description & OR $(95 \% \mathrm{Cl})$ & 1.00 & $0.32(0.18-0.58)$ & $0.10(0.04-0.23)$ & $0.17(0.09-0.35)$ & \\
\hline Education & High school in any country & $1.65(1.09-2.50)$ & & & & & \\
\hline Marital status & Married or cohabiting & $1.27(0.80-2.00)$ & & & & & \\
\hline Household members & Above 3 members & $1.35(0.83-2.19)$ & & & & & \\
\hline Employment status & Employed & $1.68(1.11-2.55)$ & & & & & \\
\hline Residential areas & Outside metropolitan & $1.72(1.14-2.58)$ & & & & & \\
\hline Sufficient income & Yes & $1.36(0.90-2.07)$ & & & & & \\
\hline Self-perceived health status & Good & $1.32(0.80-2.18)$ & & & & & \\
\hline Ever given birth & Yes & $1.13(0.62-2.06)$ & & & & & \\
\hline Ever smoked & Yes & $0.92(0.55-1.53)$ & & & & & \\
\hline Obese & $\mathrm{BMI}>30 \mathrm{Kg} / \mathrm{M}^{2}$ & $0.83(0.54-1.26)$ & & & & & \\
\hline Leisure-time physical exercise & Active & $1.53(0.93-2.51)$ & & & & & \\
\hline Any chronic illness & Yes & $1.66(1.03-2.66)$ & & & & & \\
\hline Any abortion & Yes & $1.05(0.66-1.66)$ & & & & & \\
\hline Any miscarriage & Yes & $1.19(0.76-1.86)$ & & & & & \\
\hline \multirow[t]{2}{*}{ Model $^{3}$} & & & 1.00 & $0.74(0.16-3.39)$ & $0.34(0.05-2.49)$ & $0.23(0.05-1.10)$ & 0.1642 \\
\hline & & & & \multicolumn{2}{|l|}{ Interaction terms } & & \\
\hline Marital status & Married or cohabiting* & $4.58(1.92-10.9)$ & 1.00 & $0.16(0.05-0.51)$ & $0.32(0.06-1.65)$ & $0.18(0.05-0.63)$ & 0.0103 \\
\hline Employment status & Employed* & $0.46(0.15-1.44)$ & 1.00 & $4.91(1.30-18.6)$ & $1.21(0.20-7.48)$ & $6.07(1.50-24.6)$ & 0.0225 \\
\hline Household members & Above 3 members* & $1.47(0.38-5.64)$ & 1.00 & $0.56(0.12-2.63)$ & $0.48(0.08-2.93)$ & $1.66(0.37-7.53)$ & 0.1841 \\
\hline Residential areas & Outside metropolitan* & $1.53(0.57-4.15)$ & 1.00 & $1.05(0.30-3.68)$ & $0.08(0.01-0.57)$ & $1.77(0.52-6.01)$ & 0.0130 \\
\hline Ever smoked & Yes & $3.15(1.39-7.16)$ & 1.00 & $0.25(0.08-0.75)$ & N/A & $0.13(0.03-0.58)$ & 0.0091 \\
\hline Education & High school & $1.79(1.16-2.77)$ & & & & & \\
\hline Sufficient income & Yes & $1.50(0.97-2.30)$ & & & & & \\
\hline Self-perceived health status & Good & $1.33(0-79-2.25)$ & & & & & \\
\hline Ever given birth & Yes & $1.06(0.55-2.04)$ & & & & & \\
\hline Obese & $\mathrm{BMI}>30 \mathrm{Kg} / \mathrm{M}^{2}$ & $0.81(0.52-1.25)$ & & & & & \\
\hline Leisure-time physical exercise & Active & $1.50(0.88-2.57)$ & & & & & \\
\hline Any chronic illness & Yes & $1.64(0.98-2.73)$ & & & & & \\
\hline Any abortion & Yes & $0.98(0.60-1.61)$ & & & & & \\
\hline Any miscarriage & Yes & $1.29(0.81-2.06)$ & & & & & \\
\hline
\end{tabular}

${ }^{1}$ Adjusted for age

${ }^{2}$ Adjusted for age, education, marital status, employment status, family size, residential area, sufficient income, self-rated health status, ever given birth, obesity (BMI), physical exercise, any chronic illness, any abortions, any miscarriage, and ever smoked

${ }^{3}$ Adjusted for age, education, marital status, employment status, household members, residential area, sufficient income, self-rated health status, ever given birth, obesity (BMI) physical exercise, any chronic illness, any abortions, any miscarriage, ever smoked. Including study group Interactions with: Marital status, employment status, residential areas, household members and ever smoked

$N / A$ not available due to no smokers in this group

*Interaction $p$-values (Interaction -test results)

financial hardship" [51]. This comprises the right of access to healthcare services, such as cervical screening. However, disparities in cervical screening practices could lead to underutilisation of the screening service and thus increase the incidence of, and mortality from, the disease [52]. Earlier studies have highlighted the higher risk of the disease among non-screened participants or those who seldom participate in the screening, compared to regularly screened women $[4,16,21]$. This feature exists especially among some immigrant groups, 
compared with the native population $[4,11,12,16,23]$. With immigrant population increasing, disparities that persist will increase national healthcare expenditure [52].

When observing such disparities, it is relevant to ask why some immigrant women have lower adherence to recommendations related to women's health. According to previous studies, non-adherence to screening recommendations among some immigrant groups has associations with lack of knowledge about screening, lack of disease symptoms, and religious faith. Not having a female healthcare professional to perform the screening test may also function as a barrier to screening participation [13, 14, 25, 27-29, 53]. Based on an earlier study [54], perceptions about, or differences in healthcare service practices or delivery in the country of origin of the immigrant and his/her host country might also contribute to the problem. Participants in this particular study expected their healthcare providers to take an active role in preventive healthcare advice or recommendations as it was practised in their country of origin. Two studies have demonstrated the role of healthcare providers and personal physicians; providing referrals for screening increases the likelihood of screening participation [4, 55]. Migrationrelated issues, namely, longer period of stay in the host country, younger age at migration, and higher level of acculturation, are determinants for screening participation among some immigrant groups [14, 26, 31-33]. However, in this study we did not adjust for these determinants, because our main focus was in comparison with the general Finnish population, where such variables are irrelevant.

In our study, overall, among these immigrant groups, the highest screening participation rate was observed among Russians followed by the Kurds while the Somalis had the lowest participation rate; these results are consistent with those of an earlier study [9]. These population groups have migrated from different continents and countries; thus, their cultural beliefs, norms, health beliefs, religion, ethnicity, and health-seeking behaviours, might vary $[13,14,53,54,56]$.

The relatively active screening participation among Russian women compared with other immigrant women might be partly due to their higher level of language proficiency, with about $90 \%$ understanding Finnish or Swedish, the official languages of Finland, as demonstrated in an earlier study [9]. Understanding the official language of the host country increases the likelihood of screening participation $[9,13,23,25,33,55]$. Adequate language skills enable the individual to navigate within the healthcare system for obtaining health promotion information, such as the importance and aims of the screening. Language skills also facilitate effective communication with healthcare officials [9, 32, 33, 55].
We adjusted our analyses for differences in multiple confounders, which may at least partly explain some of the disparities initially observed. For example, the association between higher screening participation and being married or cohabiting, although found only among Finns and Somalis, could explain the essential role of the husband or partner in screening participation, consistent with a previous study [53]. Further, the low screening participation found among Somali or Muslim women might be related to unfamiliarity with screening due to the unavailability of the screening programme, lack of understanding of healthcare practices, or lack of screening affordability, in their country of origin [57]. Additionally, some Somali women have poor language proficiency, low level of education, or both; thus, they are unable to obtain health information, as shown in previous studies [9, 24, 31, 33, 34]. The experience(s) of embarrassment associated with female genital mutilation (FGM) or anxiety associated with screening and unpleasant screening experience(s), or both, might influence them [24, 33]. Further, the lower screening participation rate among Somalis living outside the metropolitan areas of Finland might be related to difficulties in transportation. Similar features were presented in mammogram screening [19].

To increase cervical screening participation among these immigrant groups, promoting screening awareness, disseminating information and offering education in the immigrants' native language, as well as providing interpreters and female health professionals, are vital. Organising transportation when possible might also be helpful [24, 28, 29, 33, 34, 56, 58].

\section{Strengths and limitations of the study}

This study has a population-based design and a reasonable response rate among Russian, Kurdish, and Finnish, participants. Bilingual interviewers who spoke and understood the native language of the participants themselves interviewed the participants; most were female. This feature enhances participant willingness and enables addressing gender-related issues. It also offered an opportunity to clarify research aims or questions raised during the interview [46].

The study also has some limitations. Responses to cervical screening participation based on retrospective selfreporting might involve some recall bias [59]. Response rates differed across immigrant groups. One explanation for this might be the differences in cultural backgrounds and beliefs; their reasons for migration are different. Refugees may be more concerned about data secrecy and may harbour more mistrust towards authorities. Furthermore, the particularly low survey response rate among Somalis might bias the results and limit the statistical power of the analyses. However, this limitation was 
statistically accounted for. Nonetheless, to the best of our knowledge, ours is the first study to analyse and report disparities in cervical screening participation among immigrant groups compared with the general Finnish population.

\section{Conclusions}

Although Finland offers universal cervical screening to all eligible women, our results indicate disparities in screening participation among these immigrants and a lower likelihood of screening participation compared with the general Finnish population. To improve equity in cervical cancer screening participation, appropriate culturally tailored intervention programmes for each immigrant group might be beneficial. Further research is needed to enhance understanding of cultural and health beliefs, as well as of norms which may be specific to each immigrant group; we especially need qualitative studies.

\section{Abbreviations}

FGM: Female genital mutilation; LMICs: Low- and- middle-income countries

\section{Acknowledgements}

We gratefully acknowledge all our study participants, field workers, and experts of the study group. We acknowledge Gerald G Netto, PhD, at the University of Eastern Finland, for checking the English language of this paper.

\section{Funding}

We received no funding for the writing of this paper.

\section{Availability of data and materials}

Due to data protection regulations, the survey data are not openly shared. However, data can be obtained for research purposes. Guidelines for data use are available at the survey website: https://thl.fi/en/web/thlfi-en/researchand-expertwork/population-studies/migrant-health-and-wellbeing-studymaamu-/information-for-researchers.

\section{Authors' contributions}

EEl conceived the idea of this study, conducted the literature search, ran the statistical analyses, and drafted the manuscript. EEI, PK, and TK, participated in the conceptualized design of this work. TK provided supervision with the statistical analyses and writing of the manuscript. TH provided guidance and expertise in statistical analyses. PK provided expertise in the Maamu and Health 2011 Survey studies, acquisition of the data set, selecting, defining the variables and models for the study and in the statistical analyses as wel as contributing significantly to the writing of the paper. MK and A-M P contributed to the drafting of the manuscript. EEI, PK, TK, and TH interpreted the study results and revised its intellectual context. All the authors contributed to the writing of the paper, and reviewed and approved its final version for submission.

\section{Ethics approval and consent to participate}

For both sets of data (the Maamu study; 325/13/03/00/2009, and the Health 2011 survey 45/13/03/00/11), the coordinating ethics committee of the Hospital District of Helsinki and Uusimaa in Finland granted ethics approval. Each participant gave a written informed consent before the interview.

\section{Competing interests}

TK declares no competing interest concerning this work, but she reports having served as an occasional consultant 2012-2016 to Pfizer, a pharmaceutical company involved in nicotine dependence treatment. Other authors declare that they have no competing interests.

\section{Publisher's Note}

Springer Nature remains neutral with regard to jurisdictional claims in published maps and institutional affiliations.

\section{Author details}

${ }^{1}$ Institute of Public Health and Clinical Nutrition, Faculty of Health Sciences, University of Eastern Finland, Yliopistoranta 1, P. O. Box 1627, 70211 Kuopio, Finland. ${ }^{2}$ Department of Public Health Solutions, National Institute for Health and Welfare (THL), Helsinki, Finland. ${ }^{3}$ Department of Nursing Science, Faculty of Health Sciences, University of Eastern Finland, Kuopio, Finland.

${ }^{4}$ Department of Public Health, Faculty of Medicine, University of Helsinki, Helsinki, Finland.

Received: 9 November 2017 Accepted: 26 April 2018

Published online: 04 May 2018

\section{References}

1. Ferlay J, Soerjomataram I, Dikshit R, et al. Cancer incidence and mortality worldwide: sources, methods and major patterns in GLOBOCAN 2012. Int J Cancer. 2015;136:E359-86.

2. Torre LA, Islami F, Siegel RL, Ward EM, Jemal A. Global cancer in women: burden and trend. Cancer Epidemiol Biomark Prev. 2017;26(4):444-57.

3. Sankaranarayanan R. Overview of cervical cancer in the developing world. Int J Gynecol Obstet. 2006:95:S205-10.

4. Spence AR, Alobaid A, Drouin P, et al. Screening histories and contact with physicians as determinants of cervical cancer risk in Montreal. Quebec Curr Oncol. 2014;21(6):294-304.

5. World Health Organization. WHO guidelines for screening and treatment of precancerous lesions for cervical cancer prevention. http://www.who.int/ reproductivehealth/publications/cancers/screening_and_treatment_of_ precancerous_lesions/en/. Accessed 22 Oct 2017.

6. European commission. Cancer screening in the European Union report on the implementation of the council recommendation on cancer screening. https://ec.europa.eu/health/sites/health/files/major_chronic_diseases/docs/2017_ cancerscreening_2ndreportimplementation_en.pdf. Accessed 22 Oct 2017.

7. Hakama M, Coleman MP, Alexe D, Auvinen A. Cancer screening: evidence and practice in Europe 2008. Eur J Cancer. 2008:44(10):1404-13.

8. Vaccarella S, Franceschi S, Engholm G, Lonnberg S, Khan S, Bray F. 50 years of screening in the Nordic countries: quantifying the effects on cervical cancer incidence. Br J Cancer. 2014;111(5):965-9.

9. Idehen $\mathrm{EE}$, Korhonen T, Castaneda A, et al. Factors associated with cervical cancer screening participation among immigrants of Russian, Somali and Kurdish origin: a population-based study in Finland. BMC Womens Health. 2017;17(1):19.

10. Moen KA, Kumar B, Qureshi S, Diaz E. Differences in cervical cancer screening between immigrants and nonimmigrants in Norway: a primary healthcare register-based study. Eur J Cancer Prev. 2017;26(6):521-7.

11. Campari F, et al. Cervical cancer screening in immigrant women in Italy: a survey on participation, cytology and histology results. Eur J Cancer Prev. 2016;25(4):321-8.

12. Visioli CB, Crocetti E, Zappa M, et al. Participation and risk of high grade cytological lesions among immigrants and Italian-born women in an organized cervical cancer screening program in Central Italy. J Immigr Minor Health. 2015;17(3):670-8.

13. Marlow LAV, Wardle J, Waller J. Understanding cervical screening nonattendance among ethnic minority women in England. Br J Cancer. 2015; 113(5):833-9.

14. Ekechi C, Olaitan A, Ellis R, Koris J, Amajuoyi A, Marlow LAV. Knowledge of cervical cancer and attendance at cervical cancer screening: a survey of black women in London. BMC Public Health. 2014;14:1096.

15. Aminisani N, Armstrong BK, Canfell K. Cervical cancer screening in middle eastern and Asian migrants to Australia: a record linkage study. Cancer Epidemiol. 2012;36(6):E394-400.

16. Azerkan F, Sparen P, Sandin S, Tillgren P, Faxelid E, Zendehdel K. Cervical screening participation and risk among Swedish-born and immigrant women in Sweden. Int J Cancer. 2012;130(4):937-47.

17. Pons-Vigues M, Puigpinos-Riera R, Rodriguez-Sanz M, Serral G, Palencia L, Borrell C. Preventive control of breast and cervical cancer in immigrant and native women in Spain: the role of country of origin and social class. Int J Health Serv. 2011;41(3):483-99. 
18. Xiong H, Murphy M, Mathews M, Gadag V, Wang PP. Cervical cancer screening among Asian Canadian immigrant and nonimmigrant women. Am J Health Behav. 2010;34(2):131-43.

19. Moser K, Patnick J, Beral V. Inequalities in reported use of breast and cervical screening in great Britain: analysis of cross sectional survey data. BMJ. 2009; 338:b2025.

20. Simon J, Kiss N, Łaszewska A, Mayer S. Public health aspects of migrant health: a review of the evidence on health status for labour migrants in the European Region. Copenhagen: WHO Regional Office for Europe; 2015 (Health Evidence Network synthesis report 43). http://www.euro.who.int/ data/assets/pdf_file/0003/289245/WHO-HEN-Report-A5-1-Labour-rev1. pdf?ua=1. Accessed 1 May 2018.

21. Dugue $P$, Lynge $E$, Rebolj M. Mortality of non- participants in cervical screening: register- based cohort study. Int J Cancer. 2014;134(11):2674-82.

22. Spence $A R$, Goggin $P$, Franco EL. Process of care failures in invasive cervical cancer: systematic review and meta-analysis. Prev Med. 2007;45(2-3):93-106.

23. Van Leeuwen AWFM, de Nooijer P, Hop WCJ. Screening for cervica carcinoma: participation and results for ethnic groups and socioeconomic status. Cancer Cytopathology. 2005;105(5):270-6.

24. Abdullahi A, Copping J, Kessel A, Luck M, Bonell C. Cervical screening: perceptions and barriers to uptake among Somali women in Camden Public Health. 2009;123(10):680-5.

25. Olsson E, Lau M, Lifvergren S, Chakhunashvili A. Community collaboration to increase foreign-born women's participation in a cervical cancer screening program in Sweden: a quality improvement project. Int J Equity Health. 2014;13(1):62

26. Khadilkar A, Chen Y. Rate of cervical cancer screening associated with immigration status and number of years since immigration in Ontario, Canada. J Immigr Minor Health. 2013;15(2):244-8.

27. Vahabi M, Lofters A. Muslim immigrant women's views on cervical cancer screening and HPV self-sampling in Ontario, Canada. BMC Public Health. 2016;16:868

28. Vu M, Azmat A, Radejko T, Padela Al. Predictors of delayed healthcare seeking among American Muslim women. J Women's Health. 2016;25(6): 586-93

29. Lofters AK, Moineddin R, Hwang SW, Glazier RH. Predictors of low cervical cancer screening among immigrant women in Ontario, Canada. BMC Womens Health. 2011:11:20.

30. Azerkan F, Zendehdel K, Tillgren P, Faxelid E, Sparen P. Risk of cervical cancer among immigrants by age at immigration and follow-up time in Sweden, from 1968 to 2004. Int J Cancer. 2008;123(11):2664-70.

31. Gupta A, Ashesh K, Donna E. Cervical cancer screening among south Asian women in Canada: the role of education and acculturation. Health Care for Women International. 2011;23(2):123-34.

32. McDonald JT, Kennedy S. Cervical cancer screening by immigrant and minority women in Canada. J Immigr Minor Health. 2007;9(4):323-34.

33. Schleicher E. Immigrant women and cervical cancer prevention in the United States. Baltimore: Women's and Children's Health Policy Center, Johns Hopkins Bloomberg School of Public Health; 2007.

34. Gele AA, Pettersen KS, Torheim LE, Kumar B. Health literacy: the missing link in improving the health of Somali immigrant women in Oslo. BMC Public Health. 2016;16:1134

35. United Nations. International migration report 2015. http://www.un.org/en/ development/desa/population/migration/publications/migrationreport/ docs/MigrationReport2015.pdf. Accessed 12 Jul 2017.

36. Rechel B, Mladovsky P, Ingleby D, Mackenbach JP, McKee M. Migration and health in an increasingly diverse Europe. Lancet. 2013;381(9873): 1235-45.

37. Bhopal RS, editor. Migration, ethnicity, race and health in multicultural societies: foundations for better epidemiology, public health, and health care. Oxford: University Press; 2014.

38. Karl-Trummer U, Sardadvar S. The interplay of health, migrant status and socioeconomic status in eight EU countries. Health inequalities and risk factors among migrants and ethnic minorities. COST Series on Health and Diversity. 2012;1:79-92

39. World Health Organization. How health systems can address health inequities linked to migration and ethnicity. Copenhagen: WHO Regional Office for Europe; 2010

40. Marmot M, Allen J, Bell R, Bloomer E, Goldblatt P. WHO European review of social determinants of health and the health divide. Lancet. 2012;380(9846): 1011-29.
41. Statistics Finland. Immigration rose to a new record level in 2016. http:// www.stat.fi/til/muutl/2016/muutl_2016_2017-05-17 tie_001_en.html. Accessed 21 Sept 2017.

42. Anttila A, Nieminen P. Cervical cancer screening programme in Finland. Eur J Cancer. 2000;36(17):2209-14.

43. Finnish mass screening. Cervical cancer screening. https://cancerregistry.fi/ screening/cervical-cancer-screening/. Accessed 1 May 2018.

44. Salo H, Nieminen P, Kilpi T, et al. Divergent coverage, frequency and costs of organised and opportunistic pap testing in Finland. Int J Cancer. 2014; 135(1):204-13.

45. Arbyn M, Raifu AO, Weiderpass E, Bray F, Anttila A. Trends of cervical cancer mortality in the member states of the European Union. Eur J Cancer. 2009; 45(15):2640-8.

46. Castaneda A, Rask S, Koponen P, Mölsä M, Koskinen S. Migrant health and wellbeing. A study on persons of Russian, Somali and Kurdish origin in Finland. in: Finnish, with English abstract, report 61. Helsinki. Also available from http://urn.fi/URN:ISBN:978-952-245-739-4. Accessed 1 May 2018.

47. Koskinen S, Lundqvist A, Ristiluoma N, editors. Health, functional capacity and welfare in Finland in 2011. (In Finnish, with English abstract). Report 68 Helsinki: National Institute for Health and Welfare (THL); 2012. Also available from http://urn.fi/URN:ISBN:978-952-245-769-1. Accessed 1 May 2018.

48. Finnish Ministry of the Interior. Annual report on immigration. https://migri. fi/documents/5202425/6169001/2012+en. Accessed 9 May 2015.

49. Robins J, Rotnitzky A, Zhao L. Estimation of regression coefficients when some regressors are not always observed. J Am Statist Assoc. 1994;89(427): 846-66.

50. Graubard B, Korn E. Predictive margins with survey data. Biometrics. 1999; 55(2):652-9.

51. World Health Organization. Tracking universal health coverage: 2017 global monitoring report. http://www.who.int/healthinfo/universal_health_ coverage/report/2017/en/. Accessed 28 Mar 2018.

52. Downs LS, Smith JS, Scarinci I, Flowers L, Parham G. The disparity of cervical cancer in diverse populations. Gynecol Oncol. 2008;109(2):S22-30.

53. Basu P, Sarkar S, Mukherjee S, et al. Women's perceptions and social barriers determine compliance to cervical screening: results from a population based study in India. Cancer Detect Prev. 2006;30(4):369-74.

54. Team V, Manderson LH, Markovic M. From state care to self-care: Cancer screening behaviours among Russian-speaking Australian women. Australian Journal of Primary Health. 2013;19(2):130-7.

55. De Alba I, Sweningson JM. English proficiency and physicians' recommendation of pap smears among Hispanics. Cancer Detect Prev. 2006:30(3):292-6.

56. Samuel PS, Pringle JP, James NW, Fielding SJ, Fairfield KM. Breast, cervical, and colorectal cancer screening rates amongst female Cambodian, Somali, and Vietnamese immigrants in the USA. Int J Equity Health. 2009:8:30.

57. Sankaranarayanan R, Ferlay J. Worldwide burden of gynaecological cancer the size of the problem. Best Practice \& Research in Clinical Obstetrics \& Gynaecology. 2006;20(2):207-25.

58. Morrison T, Wieland M, Ahmed S, Rajeev C. Disparities in preventive health services among Somali immigrants and refugees. J Immigr Minor Health. 2012;14(6):968-74.

59. Lofters A, Vahabi M, Glazier RH. The validity of self-reported cancer screening history and the role of social disadvantage in Ontario, Canada. BMC Public Health. 2015;15:28.

\section{Ready to submit your research? Choose BMC and benefit from:}

- fast, convenient online submission

- thorough peer review by experienced researchers in your field

- rapid publication on acceptance

- support for research data, including large and complex data types

- gold Open Access which fosters wider collaboration and increased citations

- maximum visibility for your research: over $100 \mathrm{M}$ website views per year

At BMC, research is always in progress.

Learn more biomedcentral.com/submissions 